Goldschmidt 2021 Abstract

https://doi.org/10.7185/gold2021.5705

\section{"Critical" trace elements in major minerals: old questions, new approaches and geochemical applications}

\author{
GLEB S. POKROVSKI ${ }^{1}$, MARC BLANCHARD ${ }^{1}$, DENIS \\ TESTEMALE $^{2}$ AND JEAN-LOUIS HAZEMANN ${ }^{2}$
}

${ }^{1}$ Géosciences Environnement Toulouse - CNRS - Univ Toulouse III - IRD - CNES - OMP

${ }^{2}$ Institut Néel - CNRS

Presenting Author: gleb.pokrovski@get.omp.eu

Most trace elements in Nature are "hidden" in major sulfide, oxide or silicate minerals. Despite significant advances in microanalytical techniques over the past 20 years allowing the bulk concentration and distribution of such elements to be quantified from microscopic to mineral-deposit scale, their exact structural and redox state, the link with major elements, and the mechanisms of their uptake and release by the host mineral remain poorly known. Such knowledge is required, in particular, for the use of trace element signatures for tracing metal sources for ore deposits, reconstructing fluid evolution and metal precipitation, and for more efficient metal georessources exploration and ore processing. In-situ high-resolution synchrotron X-ray absorption spectroscopy, combined with physical-chemical and molecular modeling, is the most direct method to provide information about a trace element redox state, chemical bonding, and coordination at the atomic scale.

In this keynote contribution, we will present the example of an integrated study, benefiting from recent advances in these approaches, of a valuable trace metal commodity, gold, in ubiquitous iron sulfide and sulfarsenide minerals (arsenian pyrite, arsenopyrite and löllingite), which are the major concentrators of "invisible" gold and other chalcophile trace elements in the Earth's crust. We show that $\mathrm{Au}$ enters Asenriched $\mathrm{Fe}$ crystallographic sites of the three minerals in a formal oxidation state of $\mathrm{Au}^{\mathrm{II}}$, forming $\left[\mathrm{AuAs}_{n} \mathrm{~S}_{6-n}\right.$ ] units, whereas in As-poor pyrite $\mathrm{Au}$ is dominantly chemisorbed as $\left[\mathrm{Au}^{\mathrm{I}} \mathrm{S}_{2}\right]$ moieties in much lower concentrations. Our findings imply a universal control exerted by arsenic on gold incorporation in iron sulfides and sulfarsenides via coupled $\mathrm{Au}-$ As redox reactions, between $\mathrm{Au}^{\mathrm{I}} / \mathrm{As}^{\mathrm{III}}$ in the hydrothermal fluid and $\mathrm{Au}^{\mathrm{II}} / \mathrm{As}^{-\mathrm{I}}$ in the mineral. These reactions account for the observed variations in invisible gold contents in the minerals from different deposit types and enable quantitative prediction of $\mathrm{Au}$ uptake and release by these gold "mineral pumps" in hydrothermal systems.

Future advances of in-situ spectroscopy, coupled with laboratory experiments and physical-chemical modeling, will allow systematic quantification of other valuable critical metals hidden in iron sulfarsenide minerals, thereby enabling a better understanding of trace element geochemical cycles and improving resource assessment, exploration and recovery.

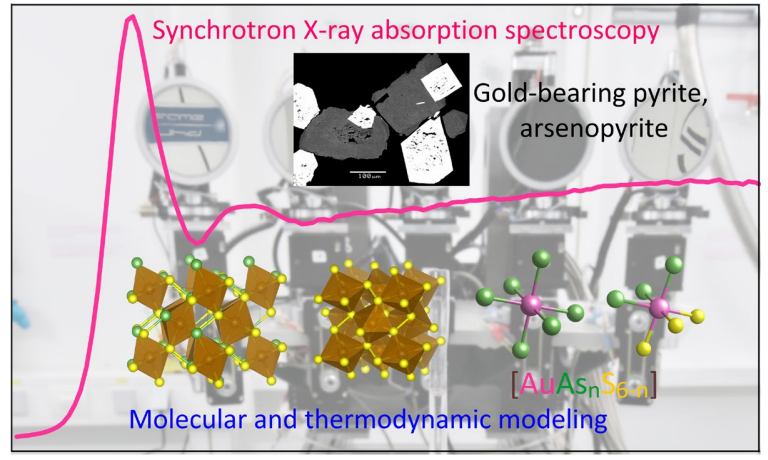

